\title{
A Cadeia Agroindustrial Orizícola do Rio Grande do Sul
}

\section{Rice Agroindustrial Chain in Rio Grande do Sul}

\author{
Sílvia Helena Galvão de Miranda ${ }^{1}$ \\ Gustavo de Souza e Silva ${ }^{2}$ \\ Maria Aparecida N. S. Braghetta ${ }^{3}$ \\ Hirina Oliveira Moraes Espósito ${ }^{4}$
}

\begin{abstract}
Resumo: No Brasil, o arroz é considerado um produto essencial na cesta básica do consumidor, sendo um dos principais alimentos consumidos diariamente pela população. Com o crescimento da produtividade, em 2004 o Brasil tornou-se autossuficiente na produção do arroz. Contudo, manteve-se como um importador líquido. A importação contribui para manter os preços domésticos em patamares mais baixos. Diante disso, julga-se importante caracterizar os principais agentes da cadeia produtiva, envolvidos na sua produção e comercialização, bem como identificar as variáveis relevantes para a formação de preço no mercado doméstico. Nesse sentido, o objetivo deste trabalho, com base em levantamentos de campo, é propor uma estrutura para a cadeia do arroz no RS, estado responsável por mais de $50 \%$ da produção nacional do produto.
\end{abstract}

Palavras-chave: Arroz; Cadeia agroindustrial. Rio Grande do Sul.

Abstract: Rice is an essential good for the Brazilian consumer's food basket, and is one of the main food consumed daily. The increasingly productivity made Brazil to reach the self-sufficiency in rice production in 2004. However, the country has continued being a net importer. Imports contribute to keep the domestic prices in lower levels. So, it is important to characterize the main agents involved in this agri-industrial chain, in the rice production and distribution, as well as identify the relevant variables to the domestic prices formation. Afterward, the objective of this paper, based on a survey, is to propose a sketch of the chain structure for the RS state that is responsible for over $50 \%$ of the Brazilian paddy rice production.

Keywords: Rice; Agri-industrial chain. Rio Grande do Sul.

JEL Classification: Q13.

1 Professora do Departamento de Economia, Administração e Sociologia - ESALQ/USP. E-mail: smiranda@esalq.usp.br

2 Coordenador Acadêmico - Instituto Educacional BMEFBOVESPA. E-mail: gssilva@bvmf. com.br

3 Pesquisadora CEPEA - ESALQ/USP. E-mail: mansbrag@hotmail.com

4 Graduanda em Engenharia Agronômica - ESALQ/USP. E-mail: esposito@esalq.usp.br 


\section{Introdução}

O estudo da estrutura e o conhecimento do funcionamento da cadeia agroindustrial do arroz do Rio Grande do Sul, que representa cerca de 53\% do arroz produzido no Brasil (CONAB, 2007), é o ponto inicial para identificar os principais elementos de formação do preço do arroz no mercado doméstico, os agentes participantes e suas respectivas relações comerciais.

Em 2004, o Brasil alcançou a autossuficiência na produção de arroz, embora ainda seja um importador líquido. Importações do produto ocorrem principalmente procedentes da Argentina e do Uruguai, países que possuem fronteira seca com o Brasil e que exportam produto da mesma qualidade do RS.

Assim, nesse período, o setor orizícola nacional apresentou um diferencial significativo entre a demanda e a oferta do produto, ocasionando um desequilíbrio relevante de preço entre os elos da cadeia produtiva e a desvalorização do produto, principalmente para o produtor rural.

Diante disso, agentes do mercado têm se voltado para discutir o potencial do mercado externo como alternativa de escoamento dos excedentes e para contribuir no equilíbrio dos preços domésticos.

Outras discussões importantes que se originam desse tema referem-se à pressão do segmento produtivo para que o governo aumente o apoio ao setor via políticas agrícolas, em particular usando a Aquisição do Governo Federal (AGF), Empréstimo do Governo Federal (EGF) e a possibilidade de intervenção através de novos instrumentos, como o mercado de opções de venda.

Indiscutivelmente, o Rio Grande do Sul, responsável por aproximadamente $50 \%$ da produção nacional nos últimos anos, representa um importante formador e referencial de preço para o mercado nacional, bem como um fornecedor fundamental do produto para todo o país, tanto em casca como beneficiado. Santa Catarina tem oscilado entre o segundo e terceiro maior produtor nacional, apresentando a maior produtividade.

Destacam-se ainda o Mato Grosso, Maranhão, Goiás e Pará, cujas áreas sofrem maiores variações ao longo do período pela competição e substituição com outras culturas. Nos últimos anos, o estado do Mato Grosso se destacou como produtor de arroz e a partir de 1999 sedimentou sua participação na produção nacional. A pesquisa de sementes que se adaptem melhor ao clima do Centro-Oeste vem dando suporte ao crescimento dessa cultura, ainda que em grande parte de qualidade diferente ao do Rio Grande do Sul. Nas demais regiões, a produção vem se desenvolvendo lentamente, apesar de percentualmente representar um grande avanço, como é o caso do Pará. 


\subsection{Objetivos}

O objetivo deste trabalho é dar um primeiro passo para descrever a cadeia agroindustrial do arroz do Rio Grande do Sul, ressaltando em particular as formas de coordenação existentes entre o setor produtivo e o industrial, inclusive cooperativo.

O instrumental descritivo da cadeia agroindustrial e a abordagem analítica da Organização Industrial permitem identificar com mais clareza as inter-relações entre os diversos segmentos, a forma como se coordenam, os gargalos da comercialização e as novas tendências que surgem nesse mercado. Ademais, poucos trabalhos têm sido publicados, no meio acadêmico, analisando a organização dessa cadeia agroindustrial.

\section{Arroz no Brasil}

O arroz, considerado uma cultura pioneira, é cultivado em todas as regiões do Brasil, avançando com a fronteira agrícola nacional, antecedendo as pastagens nas áreas recém desmatadas e se tornando uma alternativa a outras culturas nas regiões do Centro-Oeste. Ao mesmo tempo, é uma das poucas culturas possíveis na região Centro-Sul do Rio Grande do Sul, pela sua tolerância à umidade. Associa-se, em geral, à pecuária de corte extensiva. Contudo, a maior parte de sua produção concentra-se em poucos estados.

O Rio Grande do Sul é o grande produtor de arroz do Brasil, apesar do aumento da participação de outros estados ao longo da década de 90. O Estado do Mato Grosso cresce na produção da cultura, mas uma diferença básica marca o papel dos dois estados na produção nacional.

A região produtora no Rio Grande do Sul, como foi dito acima é basicamente uma região de produção de arroz e pecuária, com poucas alternativas agrícolas e, portanto, tornando pouco elástica a resposta da área plantada às oscilações de preços, em particular quando esses estão em baixa. Já no Centro-Oeste, mais especificamente no Mato Grosso, o arroz é concorrente pela terra com o milho, algodão e soja, principalmente. Dessa forma, alterações de suas cotações e preços futuros determinam uma mudança no uso da terra cultivada na safra seguinte, e uma oscilação no volume colhido, conforme se evidencia na Figura 1.

Na Figura 1 nota-se a parcela que a região Sul, principalmente o estado do Rio Grande do Sul, representa na produção nacional. Nota-se que, nos últimos anos, o perfil da produção se modificou no Brasil, com outros estados aumentando a sua produção. No entanto, a grande variação na produção do Centro-Oeste é um fator de incerteza importante que pode gerar sérios problemas de abastecimento à indústria da região. 


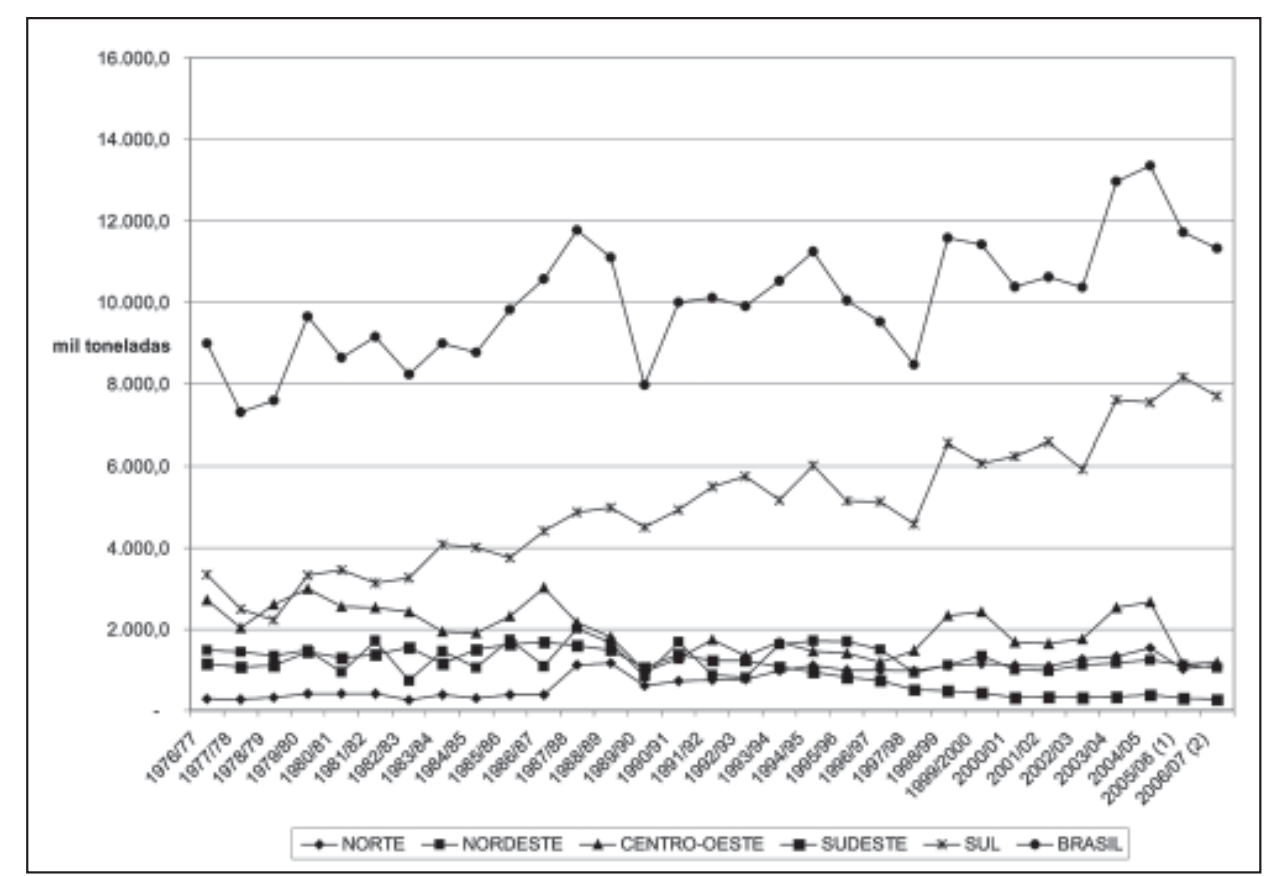

Figura 1 - Produção de arroz em casca do Brasil (Mil toneladas).

Safras 1976-77 a 2005-06. (1) Preliminar. (2) Previsão.

Fonte: CONAB (2006). Levantamento de abril/2006.

Há dois sistemas básicos de cultivo de arroz no Brasil: o de sequeiro (mais recentemente denominado de terras altas no Centro-Oeste) e o irrigado. Em número de estados, o arroz de sequeiro é o mais representativo. Quanto ao volume produzido, o arroz irrigado é principal. Avanços tecnológicos na produção de sementes permitiram diminuir a diferença entre a produtividade do arroz de terras altas e do irrigado, com melhora desse indicador para as duas regiões. No entanto, o arroz irrigado ainda continua com melhor rendimento produtivo no campo e uma relativa superioridade na qualidade, inclusive com maior uniformidade no padrão dos grãos. Com isso, a área plantada no Brasil decresceu ao longo das três últimas décadas, embora a produção tenha aumentado como foi apontado na Figura 1. A Tabela 1 aponta essa tendência, assim como a de manutenção das áreas cultivadas na região Sul e aumento apenas na região Norte. A Figura 2 apresenta a evolução da produtividade por regiões brasileiras.

Tabela 1 - Principais estados brasileiros na produção de arroz em casca - toneladas

\begin{tabular}{c|c|c|c|c}
\hline & 1990 & 1995 & 2000 & 2005 \\
\hline Pará & 148.123 & 337.758 & 403.815 & 631.724 \\
\hline Maranhão & 464.796 & 951.579 & 727.442 & 673.291 \\
\hline Santa Catarina & 567.686 & 708.427 & 799.031 & 1.055 .613 \\
\hline Mato Grosso & 420.722 & 762.327 & 1.851 .517 & 2.262 .863 \\
\hline
\end{tabular}


(continuação)

\begin{tabular}{c|c|c|c|c}
\hline Rio Grande do Sul & 3.194 .390 & 5.038 .109 & 4.981 .014 & 6.103 .289 \\
\hline Brasil & 7.420 .931 & 11.226 .064 & 11.134 .588 & 13.192 .863 \\
\hline
\end{tabular}

Fonte: IBGE

O Estado de Santa Catarina também merece ser destacado, sendo sua produtividade a maior do Brasil. O nível de tecnologia no Estado é um dos mais elevados na produção agrícola desse cereal. Em termos tecnológicos, é interessante ressaltar que esse Estado possui pesquisa financiada pelo setor privado e um amplo programa de qualidade total que atende a todo o sistema agroindustrial do arroz, inclusive colocando selos de qualidade nos produtos finais (GIORDANO; SPERS, 1998).

Em 1990-91 o consumo de arroz em casca per capita no Brasil foi de $72,96 \mathrm{~kg} /$ habitante/ano, apresentando uma tendência de queda a partir da segunda metade dessa década, e atingindo em 2003-04 a quantidade de $71,24 \mathrm{~kg} /$ habitante. A literatura sobre o setor de arroz já registra que o consumo desse produto não vem crescendo proporcionalmente ao crescimento da população. Isso, inclusive, vai ao encontro da preocupação em se desenvolver alternativas para estimular o consumo de arroz e seus usos alternativos. Yokoyama et al. (1999) alertam que, regionalmente, há grandes diferenças no comportamento dessa variável no Brasil.

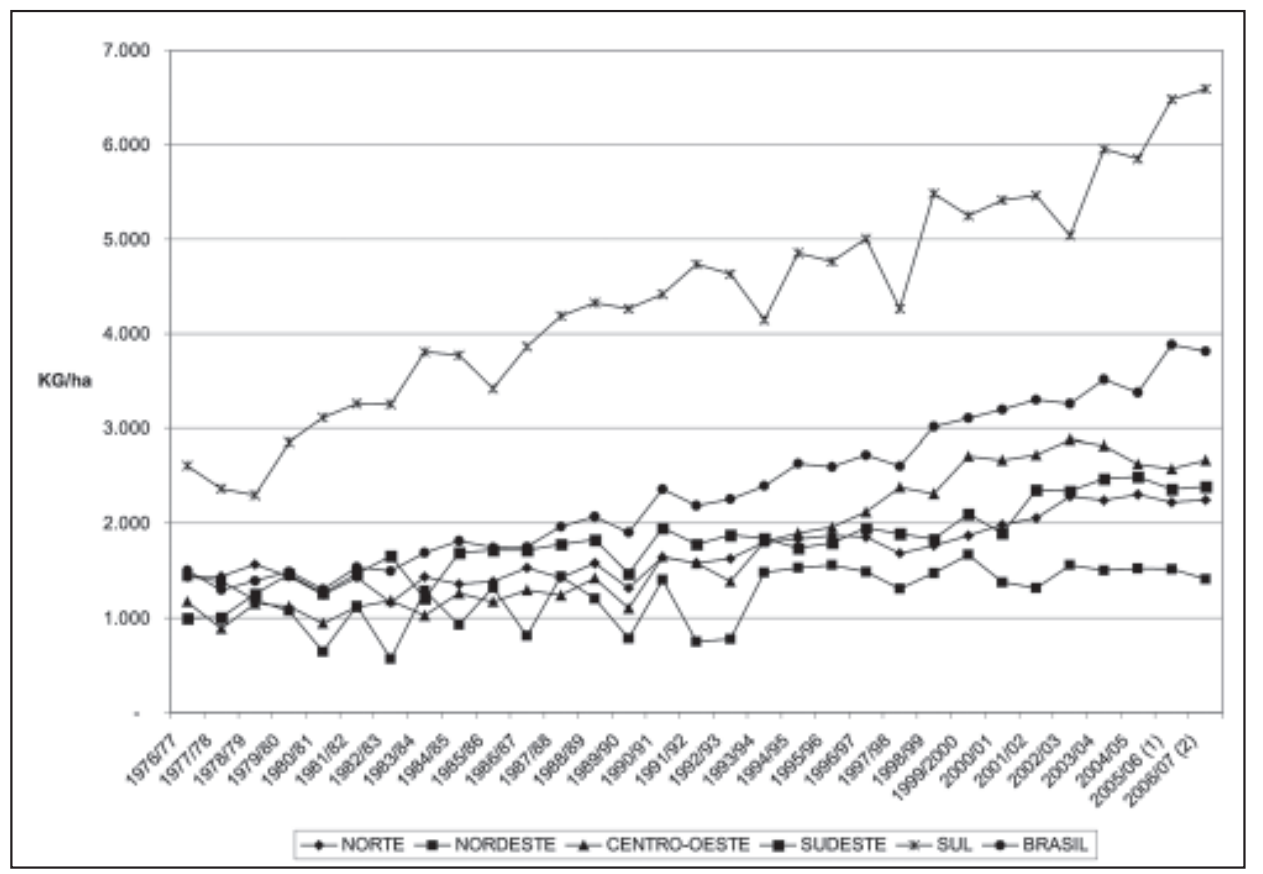

Figura 2 - Produtividade da cultura de arroz no Brasil, em kg/ha. Safras 1976-77 a 2005-06. (1) Preliminar. (2) Previsão.

Fonte: CONAB (2006). Levantamento de abril/2006. 
Para estimular o aumento do consumo de arroz, em dezembro de 2005 o Instituto Rio-Grandense do Arroz - IRGA lançou a Campanha de Incentivo ao Consumo de Arroz (CAMPANHA DE, 2007). O projeto busca mostrar as vantagens do consumo de arroz, por meio de ações de marketing. A Embrapa Arroz e Feijão, também dispende esforços em programas para promover o consumo desses alimentos, como o programa Feijão e Arroz: o par perfeito do Brasil. Esse divulga as qualidades nutricionais e as vantagens do consumo desses produtos (FEIJÃO E ARROZ, 2007).

O equilíbrio do mercado de arroz é complexo quando analisada a zona do Mercosul. Na safra 2003-04, o Brasil produziu um pouco mais do que a quantidade necessária para garantir o abastecimento. Na safra 2004-05, diante da apreciação da taxa de câmbio no Brasil, a estratégia de importação pelas indústrias do Sul do país e por alguns estados do Nordeste parece efetivamente ter sido um mecanismo para regular as margens de oferta do produto e uma oportunidade de aproveitar os preços competitivos dos países fronteiriços (Uruguai e Argentina).

As importações brasileiras de arroz podem ser verificadas pela Figura 3. Os volumes oscilam ao longo dos últimos anos em função, basicamente, da produção interna, já que o consumo pouco se alterou. Tradicionalmente, as importações complementavam a produção doméstica para atender ao abastecimento doméstico. Os principais países fornecedores para o Brasil são o Uruguai e a Argentina.

Existem muitas críticas do setor produtivo à entrada de arroz do Mercosul no Brasil diante da existência de excedentes no mercado doméstico, já que isso estaria colaborando para manter os preços do produto em casca mais baixos. Cabe ressaltar, ademais, que os países vizinhos são concorrentes também no fornecimento de arroz beneficiado.

A exportação surge como alternativa para o escoamento da produção de arroz, o que ajudaria a equilibrar o preço doméstico do arroz em casca, segundo o que o setor defende. Contudo, há um desafio importante relacionado à necessidade de ampliar o perfil da pauta exportadora de arroz, em termos de países de destino.

As exportações brasileiras têm sido pouco significativas, mas em 2006 atingiram o volume de 486,8 mil toneladas de arroz exportadas (em base casca), comparadas às 24,3 mil toneladas médias anuais, entre os anos de 1989 e 2004. Segundo Pereira et al. (2006), do total exportado em $2005,82 \%$ foram para países do continente africano. Os mesmos autores ainda apontam que o arroz quebrado respondeu praticamente pelo volume do produto exportado. 


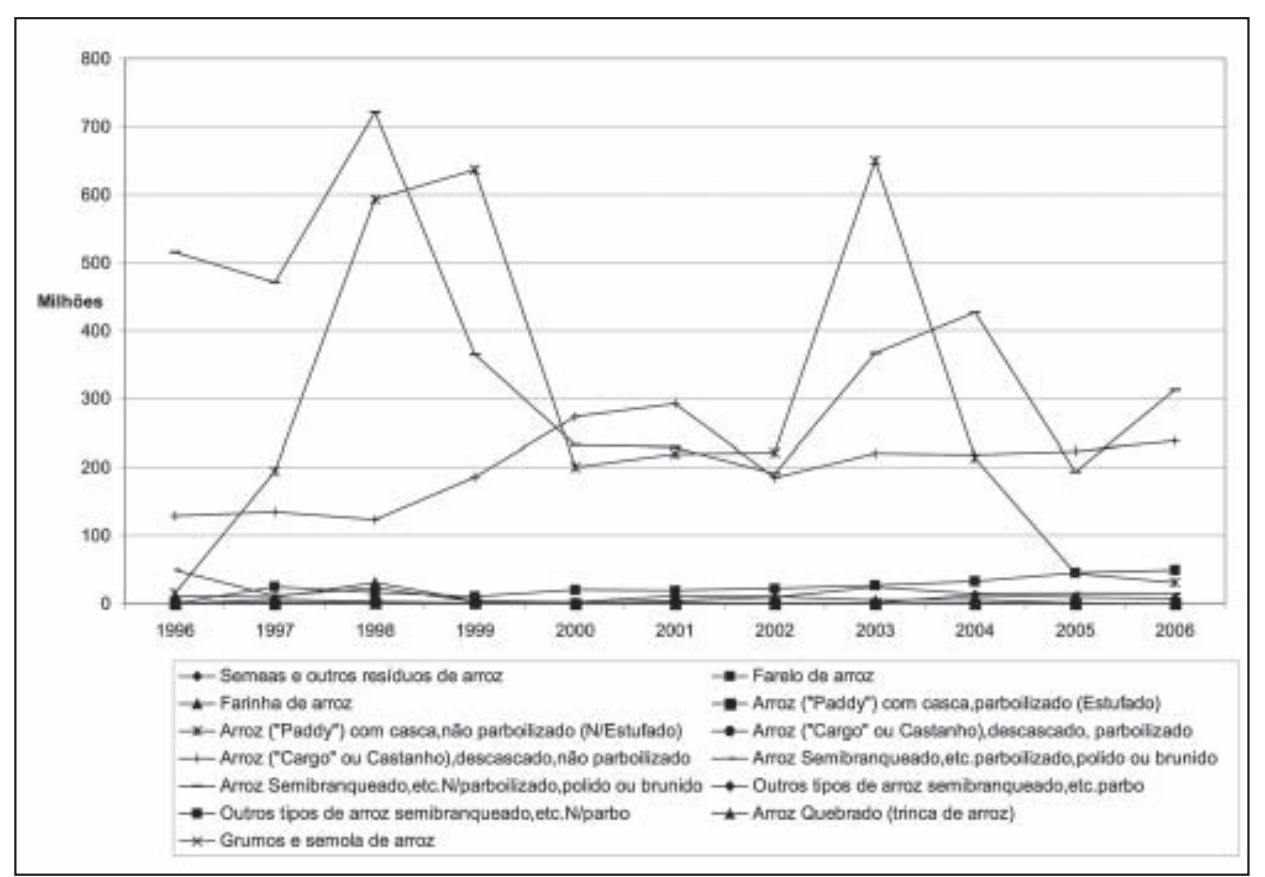

Figura 3 - Importações brasileiras de arroz, por tipo. 1996-2006, Milhões de Toneladas

Fonte: Secex - Sistema Alice (aliceweb.desenvolvimento.gov.br).

Esse perfil de exportação, caracterizado pelo produto quebrado, não contribui para reduzir o excedente de oferta no mercado interno, que permanece com disponibilidade de arroz inteiro, em casca e beneficiado. Portanto, para efetivamente contribuir para equilibrar o preço do arroz doméstico, seria necessário um incremento da exportação de produtos de melhor qualidade. A Figura 4 mostra a evolução recente das exportações de arroz, conforme os dados do Sistema Alice (MDIC, 2006).

Os mercados internacionais de arroz, ao qual o Brasil está postulando um espaço, apesar de restrito, é disputado e diversificado em termos de produtos e preços, o que gera uma competição acirrada e exige programas específicos.

\section{Cadeias Agroindustriais}

O diagnóstico da cadeia agroindustrial do arroz é importante para propor medidas públicas e estratégias privadas, que visem a melhorar a sua coordenação e eficiência diante dos novos desafios do contexto atual.

Davis e Goldberg (1957), citados por Zylbersztajn et al. (1993), conceituam a cadeia agroindustrial como uma sequência de operações interdependentes que têm por objetivo produzir, modificar e distribuir um produto. No caso do arroz, a cadeia consiste das operações de produção 
agrícola, secagem, armazenagem, beneficiamento, distribuição (atacadista e varejista), exportação e importação, basicamente. Adjacentes a essas atividades produtivas básicas estão os serviços de transporte, de crédito, de informação, entre outros.

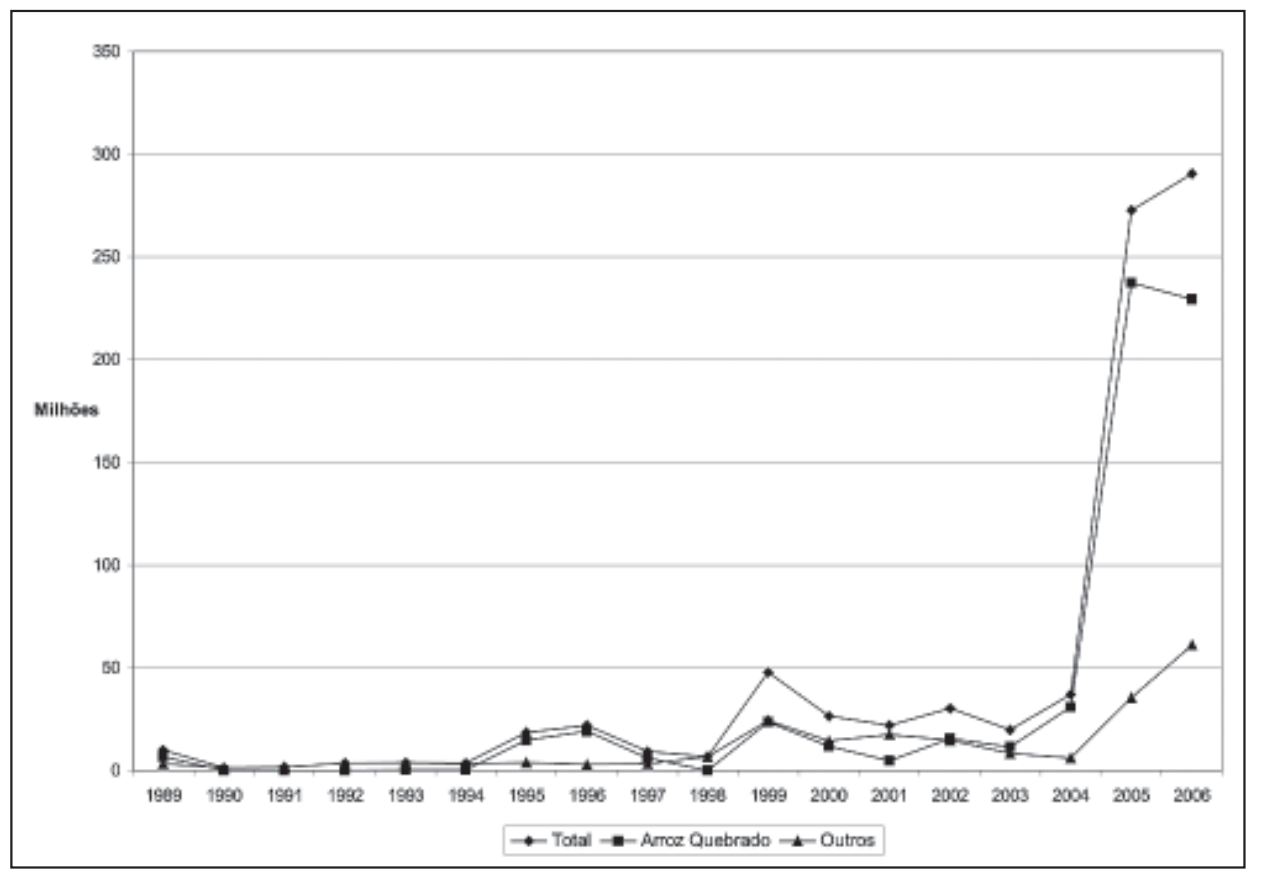

Figura 4 - Exportações de arroz, 1989-2006. Brasil, Milhões de Toneladas

Fonte: Secex - Sistema Alice (aliceweb.desenvolvimento.gov.br).

A mencionada coordenação refere-se, por sua vez, ao processo decisório que ocorre na cadeia e que envolve mais de um agente. O grau de coordenação e organização dos agentes na cadeia afeta sua reação às mudanças no ambiente externo, macro ou microeconômico. Mudanças, essas, que podem ser introduzidas pela via do mercado externo, pelas regulamentações do governo em seus diferentes âmbitos de atuação, pelas normas técnicas de iniciativa privada ou pela ação de reestruturação do mercado dada por empresas concorrentes.

Essa abordagem possibilita uma visão sistêmica das relações entre os elos e os agentes de uma cadeia agroindustrial, favorecendo a implantação de ações privadas e a formulação de políticas públicas.

Tendo como base esta abordagem de cadeias agroindustriais, dentro do aparato teórico da Organização Industrial, há poucos trabalhos que tratam com detalhamento a cadeia do arroz e as relações entre seus segmentos e agentes.

Giordano e Spers (1998) desenvolveram um estudo, que é utilizado neste artigo como base de comparação das mudanças observadas nessa cadeia, desde 1998 até 2006. O levantamento dos autores mostrou que o 
setor passava por um processo de transformação desde o início dos anos 90, com ênfase para o processo de abertura de mercado no Brasil, em particular para o Mercosul. Dentre os problemas que merecem destaque e que emergiram a partir dessa época, segundo o estudo dos autores, têm-se: a) importações crescentes; b) advento da Área de Livre Comércio das Américas - ALCA; c) endividamento; d) limitação do crescimento da produção em função de recursos hídricos e territoriais; e) consumo de arroz decrescente; f) baixa possibilidade de agregação de valor no arroz; g) sistema de classificação deveria ser mais objetivo.

As medidas que foram apontadas como necessárias por Giordano e Spers (1998) para amenizar tais problemas são: a) introduzir novas atividades agrícolas nas regiões produtoras do Sul, visando diluir custos; b) reestruturação do IRGA; c) redução na diferença de tributação entre regiões; d) expansão do "arroz de sequeiro" nas regiões de Cerrado; e) políticas de comércio exterior destinadas à proteção contra dumping; f) incentivo a um mercado futuro.

\section{Metodologia}

$\mathrm{Na}$ construção de uma representação da cadeia agroindustrial do arroz do Rio Grande do Sul, este trabalho adotou como método o levantamento de informações por meio de visitas técnicas a representantes dos diversos segmentos que formam a cadeia do arroz, como indústrias, cooperativas, corretoras e produtores rurais. Na sequência a esse levantamento inicial foram realizados diversos contatos telefônicos que também contribuíram para a elaboração da estrutura da cadeia apresentada neste trabalho.

Foram realizadas três visitas ao Rio Grande do Sul, nos meses de abril a maio de 2005, para levantar dados sobre a composição e o funcionamento da cadeia agroindustrial do arroz. As regiões visitadas conforme classificação administrativa do IRGA foram as seguintes:

1. Planície Costeira Interna;

2. Planície Costeira Externa;

3. Depressão Central;

4. Campanha;

5. Fronteira Oeste.

Os municípios visitados, com base nas informações divulgadas também pelo IRGA, representavam 83,4\% da área plantada do Estado, e 84,4\% da produção total gaúcha, segundo o Censo da Lavoura de Arroz Irrigado 
do Rio Grande do Sul - Safra 2004-05 (OLIVEIRA, 2006). No processamento, essas regiões representavam $99,88 \% .^{5}$

Uma segunda etapa de visitas foi realizada em dezembro de 2006, que, dentre outros objetivos também visava ao levantamento de informações estruturais do sistema agroindustrial do arroz.

Os dados coletados foram analisados sob a luz do conteúdo obtido em revisão da literatura especializada. É interessante notar que há grande dificuldade na obtenção de dados que permitam um melhor diagnóstico quantitativo dos segmentos de distribuição, atacado e varejo.

\section{Resultados e Discussão: A Cadeia Agroindustrial do Arroz do RS}

Os segmentos identificados neste estudo da cadeia de produção, industrialização e distribuição do arroz em casca e beneficiado do Estado do Rio Grande do Sul estão ilustrados na Figura 5.

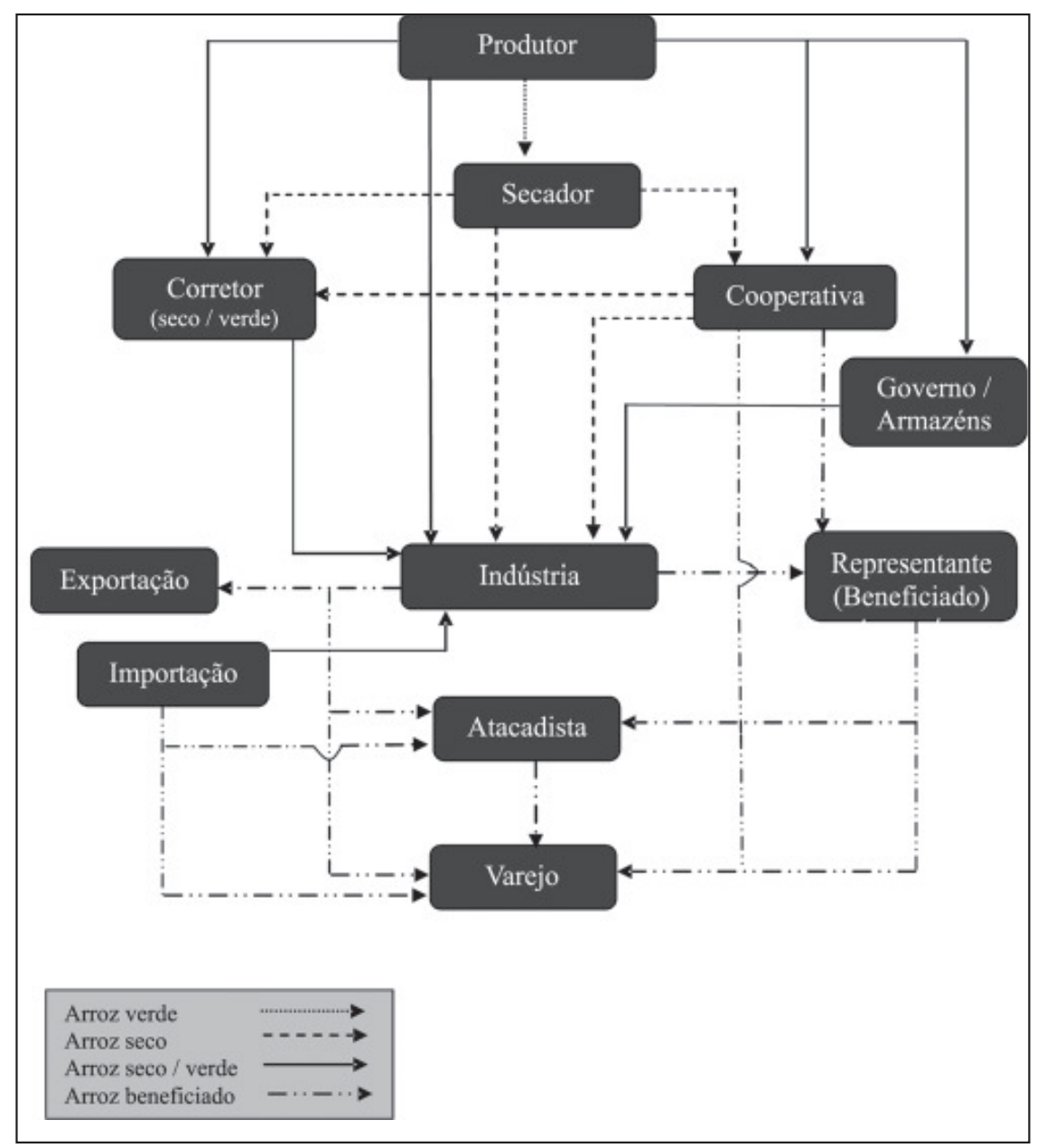

Figura 5 - Cadeia agroindustrial do arroz do Rio Grande do Sul

5 Comunicação pessoal com o IRGA, em novembro/06. 
O primeiro segmento a ser descrito é o do produtor de arroz. Em termos de posse da terra, os arrozeiros podem ser proprietários da terra, arrendatários, ou podem cultivar em áreas próprias e arrendadas. O arrendamento nesse setor é frequentemente acordado em número de sacas de arroz, podendo o acerto ser efetuado em seu valor ou sobre sua produtividade. Há também o arrendamento da água, sendo este um dos principais itens no custo de produção gaúcho.

De acordo com o Censo da Lavoura de Arroz Irrigado do Rio Grande do Sul - Safra 2004-05 (IRGA, 2006), a posse de terra, quando comparada com a posse de água, tem aspectos divergentes. Em relação à posse das terras cultivadas com arroz, 39,7\% da área é própria e 60,3\% é arrendada. No que se refere à água utilizada na produção, os números se invertem, de forma que 60,3\% da área é própria e 39,7\%, arrendada.

Outro ponto é relacionado aos financiamentos. É comum aos produtores utilizarem financiamentos de terceiros para a implantação da lavoura. Na safra 2004-05 a prática atingiu 75,6\% dos entrevistados pelo Censo elaborado pelo IRGA. A instituição que mais fornece crédito aos produtores é o Banco do Brasil, com uma participação de $34,5 \%$, seguida pelas cooperativas com $18,11 \%$, e por fornecedores de insumos, com $17,2 \%$. Deve-se notar a importância das cooperativas e segmentos de insumo como provedores de crédito.

O produtor de arroz no Rio Grande do Sul também pode ser separado entre aqueles que são mais tecnificados, possuindo infra-estrutura própria de armazenagem e secagem na propriedade rural e, no outro extremo, aqueles que precisam utilizar-se da terceirização, por exemplo, de máquinas para a colheita até para os serviços de armazenagem e/ou secagem.

De acordo ainda com o Censo 2004-05, em relação à armazenagem, a média do Rio Grande do Sul indica que apenas $28,4 \%$ dos produtores têm armazenagem própria, enquanto a proporção aumenta bastante, para $53,8 \%$, quando se trata de secagem própria. De modo geral, podese afirmar que aqueles com condições próprias de armazenagem têm melhores condições de negociar seu produto, podendo fracionar suas vendas ou aguardar o momento mais oportuno economicamente para negociar o arroz.

O produtor pode entregar o arroz ainda verde ou já seco para a indústria ou para a cooperativa. Interessante ressaltar que a colheita no Mato Grosso, segundo estado mais importante na produção nacional em período recente, ocorre a partir de janeiro e, normalmente, estendendo-se até fevereiro/março. Embora os produtores e industriais gaúchos mencionem a importação como uma das principais questões que preocupam o setor, muitos entrevistados mencionaram que, mais recentemente, cresce a atenção dos arrozeiros gaúchos com a competição do Centro-Oeste, principalmente do Mato Grosso. 
No momento da venda, o produtor rural pode recorrer ao corretor ou realizar a transação diretamente com a indústria. É importante ressaltar que a relação dos corretores com os demais elos do sistema agroindustrial do arroz são relações formais e informais, porém pouco detalhadas devido à carência de dados e informações na literatura. Esses agentes têm como principal função intermediar as transações entre produtores e indústrias, sendo essas muitas vezes localizadas em outros estados. A taxa de corretagem de 1\% em geral é paga pela indústria. Quando o negócio é feito para venda fora do estado, a taxa de corretagem pode chegar até $2 \%{ }^{6}$

Quanto ao formato das vendas, praticamente não há contratos entre produtores e indústrias visando garantir a venda/compra do arroz. Após a colheita do arroz, o produtor pode entregar seu produto a uma cooperativa, a uma armazenadora/secadora ou a uma indústria, que seca, armazena e poderá vir a beneficiar. O segmento da indústria arrozeira inclui empresas com diferentes tamanhos, infra-estrutura e possibilidades de transformação do produto.

As grandes indústrias e mesmo as médias caracterizam-se por uma alta tecnologia, parte da qual é importada, na forma de máquinas para classificação e embalagem do arroz beneficiado, por exemplo. Quanto à concentração da agroindústria do arroz no Rio Grande do Sul, cabe ressaltar que Giordano; Spers (1998) já haviam identificado que o processo de concentração industrial e das empacotadoras era uma tendência relevante para essa agroindústria.

Durante a safra, o produtor deixa o arroz armazenado nas indústrias, armazéns/secadores ou cooperativas, sem fechar o negócio de venda, ou mesmo sem negociar um valor, uma referência de preço ou uma data futura fixa para realizar a transação. Dessa forma, o produtor permanece livre para comercializar o arroz em casca com qualquer outra empresa. Ao desejar fechar o negócio com a empresa onde o produto está armazenado, basta que as duas partes estejam de acordo entre si. Porém, segundo o levantamento de campo, dificilmente um produtor retira o arroz de uma indústria para vender a outra, pois estaria sujeito à cobrança dos custos de armazenagem e, quando o caso, de secagem. Nessa situação, o produtor poderia perder a vantagem de um preço mais atrativo de comercialização devido aos custos. O sistema de armazenagem e secagem do arroz é uma questão bastante relevante para se compreender a formação de seus preços no Estado, já que grande parte dos produtores tem necessidade de entregar o produto para armazenamento nas beneficiadoras, que detêm parte significativa da capacidade de estocagem de arroz. Essa necessidade do produtor acaba por criar relações contratuais não formais, mas que na

Valores obtidos nos levantamentos de campo no primeiro semestre de 2005. 
prática do mercado acabam funcionando como se fossem. É a figura do que se denomina a "entrega do arroz em depósito na indústria".

Existe também a figura do secador, apresentada na Figura 5, cuja função na cadeia é receber, secar e armazenar o arroz para o produtor, que comercializará o produto mais tarde. Em algumas situações, esses secadores acabam auxiliando o produtor quanto às informações de mercado para a comercialização. Há cooperativas que podem se enquadrar nesse tipo de serviço, não comercializando para o produtor, mas colaborando no processo como um locus agregador de dados e informações, bem como de difusão das mesmas. O secador ou a cooperativa, quando exerce apenas a função de secagem e armazenagem, pode entregar o arroz seco para a indústria, via corretor ou diretamente.

Muitas cooperativas no Rio Grande do Sul já industrializam o produto e comercializam-no como beneficiado, com marca própria ou de terceiros. $\mathrm{Na}$ Tabela 3 pode-se observar que, dentre os 10 maiores grupos beneficiadores, três são cooperativas que beneficiam e vendem o arroz para atacado e varejo. A tabela mostra que, em 2005, esses 10 maiores grupos representavam $48 \%$ de todo o processamento do estado gaúcho. Segundo Giordano e Spers (1998), em 1993 e 1996, as 10 maiores empresas do Rio Grande do Sul tinham uma participação no mercado de 31\% e 39\%, respectivamente.

As cooperativas do setor arrozeiro têm um papel bastante relevante na comercialização do produto gaúcho. Além da função de secagem, armazenagem, beneficiamento e distribuição do arroz beneficiado que já foram mencionadas, algumas cooperativas exercem funções de crédito, compra de insumos, assistência técnica e outros serviços aos seus cooperados.

Tabela 2 - Os 10 maiores grupos de beneficiamento do RS em 2005

\begin{tabular}{|c|c|c|c|c|}
\hline Ordem & Empresas & & & Ano:2005 \\
\hline & & Total $^{1}$ & Acumulado & Participação \\
\hline 1 & Camil Alimentos S/A & 9.684 .541 & $11,28 \%$ & $11,28 \%$ \\
\hline 2 & $\begin{array}{c}\text { Josapar-Joaquim Oliveira S/A } \\
\text { Participações }\end{array}$ & 7.420 .932 & $19,93 \%$ & $8,65 \%$ \\
\hline 3 & Pirahy Alimentos Ltda. & 5.658 .931 & $26,53 \%$ & $6,59 \%$ \\
\hline 4 & $\begin{array}{l}\text { Cooperativa Arrozeira Extre- } \\
\text { mo Sul Ltda. }\end{array}$ & 3.354 .332 & $30,44 \%$ & $3,91 \%$ \\
\hline 5 & Camaquã Alimentos Ltda. & 2.702 .534 & $33,58 \%$ & $3,15 \%$ \\
\hline 6 & $\begin{array}{l}\text { Cooperativa Agroindustrial } \\
\text { Alegrete Ltda. }\end{array}$ & 2.693 .780 & $36,72 \%$ & $3,14 \%$ \\
\hline 7 & Nelson Wendt $\mathcal{E}$ Cia Ltda. & 2.513 .378 & $39,65 \%$ & $2,93 \%$ \\
\hline 8 & Santa Lúcia S/A & 2.433 .649 & $42,49 \%$ & $2,84 \%$ \\
\hline
\end{tabular}


(continuação)

\begin{tabular}{c|c|c|c|c}
\hline 9 & Urbano Agroindustrial Ltda. & 2.432 .735 & $45,32 \%$ & $2,83 \%$ \\
\hline 10 & $\begin{array}{c}\text { Cooperativa Triticola Sepeense } \\
\text { Ltda. }\end{array}$ & 2.321 .719 & $48,03 \%$ & $2,71 \%$ \\
\hline
\end{tabular}

${ }^{1}$ beneficiamento - sacos de $50 \mathrm{~kg}$

Fonte: IRGA publicado em Lavoura Arrozeira, maio/2006.

Há cooperativas muito grandes com marcas próprias fortes, como é o caso da Cooperativa Extremo Sul (Pelotas), da Cooperativa Tritícola Sepeense (São Sepé) e da Cooperativa Arrozeira Palmares (Palmares do Sul). Há cooperativas que industrializam marca de terceiros, como é o caso da Cooperativa Agroindustrial de Alegrete (CAAL), que tem uma joint-venture com a SLC Alimentos. A CAAL beneficia o arroz com a marca da SLC e essa é responsável pela comercialização.

No cenário das marcas, sendo próprias ou de terceiros, encontram-se as regionais que se apresentam bastante competitivas, uma vez que têm a vantagem de um menor custo logístico, por situarem-se mais próximas dos centros consumidores. Marcas regionais também têm menor custo com marketing, pois não visam um amplo mercado, quando comparado ao das marcas nacionais (PROJETO ARROZ BRASILEIRO, 2007). É interessante notar que algumas das pequenas e médias arrozeiras gaúchas explicitam que adotam uma política de precificação de compra de sua matéria-prima baseada no preço da empresa líder em sua região.

As indústrias/cooperativas podem produzir arroz branco, parboilizado, integral ou uma proporção entre eles. Em 2003, conforme estatísticas do IRGA, havia um número expressivo (282) de unidades industriais, embora menos de $10 \%$ delas representassem mais de $60 \%$ do volume beneficiado. Anteriormente ainda, na safra 1996-97, havia 383 engenhos no estado (IRGA, 2004). Acompanhando os dados do Instituto, é possível verificar que o número de unidades ativas vem realmente diminuindo, aumentando a concentração no setor industrial do Rio Grande do Sul.

Segundo os levantamentos de campo em 2005, em entrevistas a alguns agentes do mercado, percebeu-se que houve, há alguns anos, um movimento de deslocamento das indústrias para outros Estados (CentroOeste) e também para o Mercosul (Argentina e Uruguai). Ambas as regiões concorrem com a lavoura gaúcha na comercialização do produto beneficiado no Sudeste e nos estados do Norte e Nordeste do Brasil. Já no caso do Mercosul, esse concorre também como fornecedor de arroz em casca para a própria indústria brasileira. Observa-se que quando há pressão ascendente nos preços do arroz em casca principalmente no mercado gaúcho, mesmo diante de disponibilidade do produto nacional, as empresas importam o cereal dos países vizinhos.

É importante mencionar que, durante as entrevistas, ficou evidente a preocupação de algumas grandes empresas em promover a qualidade na 
produção e beneficiamento do arroz. Essa iniciativa das empresas muitas vezes se torna explícita na adoção de padrões de qualidade superiores aos que hoje vigoram pela Resolução Oficial do Governo, e que dita as normas para políticas agrícolas de crédito e preço de comercialização do produto em casca, por exemplo.

A valorização da qualidade refere-se às estratégias relacionadas ao pagamento de prêmios sobre o preço do arroz com maior proporção de grãos inteiros ou com menos defeitos. Atualmente, em algumas das regiões produtoras/industriais do Rio Grande do Sul, empresas pagam adicionais sobre o preço para alguns cultivares específicos. Nos últimos anos, as variedades sujeitas a um prêmio, em algumas regiões arrozeiras, são a IRGA 417 e a 409. Esses prêmios, segundo levantamentos do CEPEA (2006) desde 2005 , podem chegar a adicionais de $R \$ 1,00$ a $R \$ 2,00$ por saca, sobre 0 preço da qualidade de referência, dada pelo Indicador de Preços do Arroz BMËF-CEPEA/ESALQ.

O representante de vendas foi identificado como o segmento intermediário das marcas importantes de arroz beneficiado em outros Estados, como a Broto Legal e a Cristal, de Santa Cruz do Rio Pardo-SP e de Goiás, respectivamente. Segundo os entrevistados, os representantes adquirem a matéria-prima no Rio Grande do Sul e também no Mercosul. Esses agentes são responsáveis pela compra do produto, e em algumas situações também pelo transporte; isso apesar de, em geral, a empresa compradora se encarregar do frete quando o arroz é exportado para outros Estados. Além disso, podem ou não representar exclusivamente uma determinada indústria.

Cabe destacar como relevante na cadeia, de acordo com Giordano e Spers (1998), o baixo valor do produto final como sendo uma característica do arroz, o que requer maior eficiência em todas as operações realizadas, já que há poucas possibilidades de diferenciação e agregação de valor.

Assim, posicionamento geográfico é um fator essencial para a competitividade nesse setor, considerando-se que os custos de transporte têm um peso considerável no valor final do produto. Diante disso, os autores constataram que algumas empresas gaúchas adotaram a estratégia concorrencial de investir em indústrias na cidade de São Paulo, procurando posicionar-se junto ao mercado consumidor do eixo São Paulo-Rio de Janeiro. Outras empresas contam, inclusive, com um terminal ferroviário dentro de suas plantas, barateando custo de transporte e provendo maior flexibilidade no fornecimento.

No chamado ambiente organizacional, há também suas instituições representativas como a Federação das Cooperativas de Arroz do Rio Grande do Sul - Fearroz - e a Federação dos Arrozeiros do Rio Grande do Sul - Federarroz-, entidades específicas para o setor. Há outras de atuação mais geral para o agronegócio, como a Federação de Agricultura do Rio 
Grande do Sul - Farsul - e a Sindicato e Organização das Cooperativas do Estado do Rio Grande do Sul - Ocergs -, dentre outras de importância regional. O IRGA, entidade pioneira de representatividade de classe e com o objetivo de defesa dos segmentos da orizicultura, foi criado a partir do Sindicato do Arrozeiro do Rio Grande do Sul, em junho de 1926.

Apesar dos segmentos de atacado e de varejo não terem sido alvos de avaliação detalhada neste trabalho, pelas visitas realizadas constatou-se que grandes atacadistas, inclusive com marcas fortes, compram o arroz do Rio Grande do Sul para processar ou para embalar com suas marcas. Algumas indústrias e cooperativas têm investido em colocar representantes de vendas em outros estados do Brasil. Esses atacadistas podem representar tanto o mercado consumidor direto, como aquelas empresas que trabalham com cestas básicas como a Alcampi, importante compradora de arroz de alta qualidade do estado gaúcho.

O varejo é o segmento que dá a sinalização, semanalmente, sobre as possibilidades de comercialização. De acordo com os levantamentos, há indicações de que na comercialização do arroz as indústrias/cooperativas têm pouco poder de barganha junto ao varejo, ajustando o preço de venda do beneficiado com mais dificuldade do que o ajuste do preço pago ao produtor. Isso resulta numa maior rigidez nas margens de comercialização da indústria no repasse ao varejo, segundo pesquisas realizadas junto ao setor.

Ademais, é interessante notar que resultados de um estudo sobre margens de comercialização para arroz indicaram que, a partir de 2003, as margens relativas do varejo e do atacado apresentaram comportamentos distintos, sendo a primeira com tendência de crescimento e a segunda de diminuição (MIRANDA et al., 2006).

No varejo, no que tange ao comportamento dos consumidores quanto às marcas, algumas empresas conseguiram certo grau de diferenciação no mercado de arroz. Nesse caso, essas marcas podem ser comercializadas com um prêmio sobre seu preço no varejo, e conseguem manter a fidelidade de seu nicho de consumidores. Ademais, nota-se que esse comportamento evidencia um perfil regional de preferências. É o caso do arroz Prato Fino, muito valorizado no mercado de São Paulo, capital e interior. Há dominância de certas marcas em alguns mercados importantes das regiões metropolitanas do Brasil, como Belo Horizonte, São Paulo e Rio de Janeiro. Ainda segundo o levantamento, o mercado varejista de São Paulo é um dos mais complexos para se atuar.

Segundo Giordano e Spers (1998), compradores constantes de arroz como as empresas fornecedoras de cestas de alimentação nem sempre encontram o produto que desejam ofertados no mercado. Há poucos anos, o comprador de cesta básica negociava por preço para que pudesse oferecer vantagens dessa natureza aos seus funcionários. 
No início da segunda metade da década de 90, de acordo com informações do próprio setor aos autores mencionados, os clientes desse produto começaram a se diferenciar exigindo uma pauta de produtos básicos com uma melhor qualidade. Assim, o perfil de compra do arroz parece ter se modificado, não só pelas mudanças no consumo doméstico mas também pelo consumo institucional.

Há algumas diferenças regionais no produto distribuído pelo atacado e varejo, segundo o setor produtivo e industrial no Rio Grande do Sul. No Sudeste, o arroz beneficiado é comercializado basicamente em sacos de $5 \mathrm{~kg}$, preteridos no Nordeste pelas embalagens menores de 1 e $2 \mathrm{~kg}$. Em termos de origem do arroz, o produto do Centro-Oeste tende a ter sua distribuição concentrada no Norte e Nordeste, mercado consumidor menos exigente quanto à qualidade em contraposição ao preço, embora também concorra com o arroz do Sul nos Estados da região Sudeste, em particular em São Paulo e Minas Gerais.

Há registros na literatura de que uma das dificuldades do sistema agroindustrial do arroz no Brasil é a baixa diferenciação do produto e uma classificação baseada em atributos extrínsecos, basicamente na parcela de grãos quebrados (GIORDANO $\mathcal{3}$ SPERS, 1998). Esse critério ainda é utilizado no sul do país para precificar o arroz. Já na região do Mato Grosso, mais do que a proporção entre grãos quebrados e inteiros, o elemento essencial é a variedade do arroz. Ou seja, se a variedade produz um grão longo ou longo fino, este é o fator que definirá a questão de preço pago pela indústria.

No estudo de Giordano e Spers (1998) sobre o Sistema Agroindustrial do Arroz, foi ressaltado que o setor vinha passando por intensas mudanças desde o início dos anos 90, as quais foram promovidas pela abertura econômica e pela queda das barreiras tarifárias sobre os produtos do Mercosul. As importações crescentes e em volumes significativos de arroz foram apontadas como um dos principais problemas para a competitividade desse sistema agroindustrial.

O preço do arroz no mercado gaúcho depende certamente da oferta em cada safra, mas também dos níveis de estoques de passagem, públicos e privados (proprietários, cooperativas e indústrias). Uma limitação é que os dados sobre estoques privados são, no geral, muito pouco conhecidos. As mudanças de clima na época de plantio, de enchimento dos grãos e da colheita podem afetar positiva ou negativamente os preços no mercado físico do Rio Grande do Sul.

Muitos agentes de mercado estão, atualmente, sensibilizados pela importância do acompanhamento da produção e comercialização dos produtos no Mercosul e no Mato Grosso. Em particular, aumenta a consciência do setor sobre a relevância do arroz de terras altas como concorrente do arroz do Sul. 
A Política Agrícola estabelecida pelo Governo Federal todos os anos, com previsões de Aquisição do Governo Federal (AGF) e de preço mínimo para vigorar na safra seguinte, é outro fator de suma importância. Os produtores acompanham rotineiramente as liberações de recursos do governo, que acabam por influenciar as expectativas dos produtores e, por conseguinte, sua postura em relação aos mercados. Adicionalmente, a renegociação das dívidas agrícolas com o governo é outro elemento essencial para a compreensão dos preços e da evolução da produção do arroz no Rio Grande do Sul no curto prazo (safra/entressafra).

Os tipos existentes de arroz branco e de parboilizado são os Tipos 1 a 5 e Abaixo Padrão (AP), conforme legislação da Portaria n 269/88. Os Defeitos Gerais Agregados (DGA) definem o critério básico para classificação dos tipos de arroz beneficiado, referindo-se à quantidade dos diferentes defeitos registrados no produto. O tipo 1 é a categoria de mais alta qualidade, segundo o critério oficial de classificação de arroz.

Como já foi dito, a classificação definida nessa Resolução tem sido muito questionada pelos segmentos do setor; é considerada ultrapassada de modo que as indústrias acabam criando categorias próprias, com qualidade considerada superior à definida para o Tipo 1 da Portaria 269/88, denominando-os como tipo superior, premium, entre outras designações.

Essa questão de rendimento e qualidade associada a defeitos do cereal é de extrema relevância para tratar de quaisquer estratégias de concorrência internacional que se venham a cogitar, ou mesmo para se discutir um melhor controle de qualidade doméstica e uniformização de produtos.

O frete é outra variável de peso na formação do preço do arroz em casca, comercializado internamente no Estado ou fora. É variável em função de diversas condições: época do ano, sendo sempre mais elevado durante a safra; disponibilidade de frota de caminhões na região, embora muitos produtores, cooperativas e indústrias tenham veículos próprios; distâncias e condições das estradas.

Coincidindo com a época de colheita de outras culturas, como a soja, por exemplo, os fretes para transportar arroz em algumas regiões do Rio Grande do Sul ficam pressionados pela concorrência com outros produtos. Esse é um comportamento também presente no Mato Grosso, onde a pressão é até maior, não só por fretes mas também por armazéns.

Outra região que apresenta um comportamento de demanda por fretes diferenciados é a Fronteira Oeste, em particular as produções nos arredores de Uruguaiana, podem beneficiar-se da ferrovia. Essa linha férrea transporta o arroz até São Paulo para ser beneficiado. É importante mencionar que há, nas regiões de Uruguaiana e Alegrete, indústrias e cooperativas com a ferrovia passando por suas unidades, o que certamente lhes confere uma vantagem competitiva. 
Quanto à produção no Rio Grande do Sul, vale a pena comentar que a maior parte do arroz produzido na região Planície Costeira Externa é processada em Santa Catarina e outros estados, pela vantagem da proximidade com esses mercadose, principalmente, pela qualidade considerada a mais alta do Estado. $\mathrm{O}$ arroz nessa região, que se situa entre o Oceano e a Lagoa dos Patos, atinge rendas e rendimentos médios mais altos do que no restante do Estado, em função principalmente do clima.

\section{Considerações Finais}

Há poucos trabalhos acadêmicos na literatura brasileira descrevendo a cadeia agroindustrial do arroz, seus desafios e oportunidades. O Brasil é um grande produtor, mas também grande consumidor de arroz e apenas recentemente passou a gerar excedentes exportáveis do cereal. Apesar disso, ainda importa arroz em casca e beneficiado, situação, essa, que incomoda o setor produtivo, mas que é resultante de características muito próprias desse setor, em particular no Rio Grande do Sul, estado produtor de $53 \%$ do total nacional.

O arrozeiro lida com diversos desafios na programação de plantio e colheita do grão. Além das adversidades do clima, a falta de coordenação entre os próprios produtores, a diversidade de condições de produção entre as várias regiões, e as diferenças de infra-estrutura geram ao produtor uma maior dificuldade de programação de suas vendas. A demanda do setor pela intervenção, via políticas agrícolas (AGF, Leilão de Opção de Venda, EGF), ainda é relativamente significativa. A indústria gaúcha é composta por grandes grupos, mas também por pequenos e médios engenhos. Verifica-se que ocorre um processo de concentração industrial ao longo dos últimos anos, inclusive com participação das cooperativas, atualmente com um papel muito importante como beneficiadoras e distribuidoras de produtos, inclusive com marca própria.

Outra questão determinante identificada é que no Rio Grande do Sul são raros os exemplos de contratos entre produtores e indústrias. Portanto, não há garantias de compras e vendas por parte dos parceiros, embora se verifiquem relações de confiança e fidelidade entre agentes que comercializam há muito tempo. Uma figura relevante é a da entrega de arroz em depósito nas indústrias e cooperativas, para fechamento de negócios em uma data que fica em aberto, inclusive, sem obrigatoriedade de vir a ocorrer.

Segundo a indústria, de modo geral os preços praticados na venda do arroz beneficiado são limitados, por um lado pela oferta do arroz verde (na safra) e do arroz em casca, e de outro, pelas pressões do varejo, dependente das condições de comercialização nos grandes centros 
urbanos. A falta de coordenação para frente - atacado e varejo - e para traz - produtores - torna o setor industrial refém das oscilações de demanda, apesar do arroz beneficiado possibilitar um maior período de armazenamento.

Os setores varejista e atacadista para o arroz foram pouco discutidos até porque carecem de literatura especializada, requerendo levantamentos de campo que permitam melhorar o desenho de sua estrutura, organização, coordenação com outros segmentos e estratégias de concorrência.

O varejo tem influência significativa sobre a determinação do preço de venda das beneficiadoras do arroz em casca. Para os produtores e indústrias do Rio Grande do Sul, o grande varejo da região Sudeste é determinante, tanto que, segundo a maioria dos agentes de mercado entrevistados, os estímulos para a mudança semanal do preço do arroz em casca ocorrem a partir das terças-feiras, muito em função do que se passa no varejo no final de semana antecedente. No restante da semana, as variações de preço seriam marginais.

Contudo, um desafio que se apresenta à cadeia do arroz é avaliar a importância e a potencialidade dos novos canais de comercialização, como os que incorporam as empresas fornecedoras de refeições. Como compradores institucionais, com parcela crescente do mercado de alimentos nos últimos anos, devem ser considerados nos programas que o setor desenvolve a fim de estimular o consumo de arroz.

As exportações de arroz do país ainda são incipientes e mesmo tendo aumentado nos últimos dois anos, concentra-se em produto de baixo valor agregado, o arroz quebrado. O setor terá, entre outros, o desafio de reduzir os custos de produção, equacionar as questões relacionadas à tributação, que podem não só prejudicar a competitividade, mas também, atualmente, têm gerado problemas de viés na própria comercialização doméstica devido à Guerra Fiscal.

A eficiência produtiva, através da redução dos custos de produção e comercialização deve ser um objetivo maior para os produtores nacionais. Isso não só pelos efeitos sobre sua competitividade em relação aos parceiros do Mercosul, já que em qualidade os produtos se equiparam, mas também para melhorar a rentabilidade do negócio.

Embora o segmento produtivo, em particular o gaúcho, ainda insista que as importações são um grande problema, pois deprimem os preços domésticos, já há uma conscientização crescente de que o Mato Grosso e os estados do Centro-Oeste são os novos focos de preocupação em termos de concorrência no setor. Nessa região, produz-se hoje o arroz de terras altas, cuja qualidade melhorou muito nos últimos anos, em relação ao tradicional arroz de sequeiro, mas que ainda tem dificuldade para competir com o agulhinha gaúcho nos principais mercados consumidores do Sudeste. 
Assim, diversas variáveis afetam a determinação de preços no mercado de arroz em casca do Rio Grande do Sul, essas estando diretamente relacionadas à oferta e demanda no estado, em outras unidades da federação e sua interface com o mercado internacional, no qual certamente a taxa de câmbio, como ocorre para todo o agronegócio, passa a ser variável essencial de competitividade.

Este trabalho é uma primeira aproximação, e mais recente, do desenho da cadeia agroindustrial moderna de arroz. Há uma área promissora de estudos a serem desenvolvidos, analisando as inter-relações entre os segmentos que compõem esse setor, e seus desafios.

Destacam-se especialmente os desafios para a articulação entre os elos da cadeia e para a criação de mecanismos que reduzam os riscos para os agentes, sejam através de contratos a termo, da criação de um mercado futuro para o arroz no Mercosul, da formalização das relações já existentes entres os elos; ou até mesmo do desenvolvimento de novas formas de relação entre a indústria, produtores e os segmentos varejistas. Mais além, há o desafio de se ajustar ao processo crescente de concentração, verticalização e a necessidade de uma gestão mais eficiente que se verifica recentemente nessa cadeia agroindustrial, a exemplo de muitas outras.

\section{Referências}

ALMEIDA, P. N. A. Fontes de crescimento e sistema produtivo da orizicultura no Mato Grosso. Dissertação de mestrado - ESALQ/USP, Piracicaba. Dez./2003. 230p.

CAMPANHA DE Incentivo ao Consumo de Arroz. IRGA. 2005. Disponível em: <http://200.96.107.174/coma-arroz/index.php> Acesso em março/2007.

CENTRO DE ESTUDOS AVANÇADOS EM ECONOMIA APLICADA. Informativo CEPEA - ARROZ. Análise Econômica Semanal - Arroz em Casca. CEPEA: Piracicaba. Vários números. 2006.

COELHO, P. F. S. Comercialização do arroz irrigado com enfoque na exportação. IRGA: Porto Alegre. 2006. 10p.

COMPANHIA NACIONAL DE ABASTECIMENTO. CONAB. Disponível em: < http://www. conab.gov.br/> Acessos em julho/2006 e 2007.

FEIJÃO E ARROZ: o par perfeito do Brasil. Embrapa. Disponível em: < http://www.cnpaf. embrapa.br/parperfeito/index.htm > Acesso em março/2007.

FERREIRA, C. M; SOUSA, I. S. F.; VILLAR, P. M. Desenvolvimento Tecnológico e Dinâmica da produção do arroz de terras altas do Brasil. Embrapa Arroz e Feijão/Cepea/Cirad: Santo Antônio de Goiás. 2005. 118p.

FOOD AND AGRICULTURAL ORGANIZATION. FAO. International Year of Rice 2004. Disponível em: <http://www.fao.org/rice2004/en/f-sheet/factsheet2.pdf> Acesso em março/2007.

. FAO Rice Market Monitor - Dezembro 2006. Disponível em: < http://www.fao. org/ES/ESC/en/20953/21026/highlight_23001en.html>. 
FAOSTAT. Disponível em: < http://faostat.fao.org/faostat/collections?version=e $\overline{\mathrm{xtE}}$ hasbulk $=0>$ Acesso em agosto/2005.

GAMEIRO, A. H.. A força das marcas regionais. Disponível em: < http://www.arroz.agr.br/ site/arrozemfoco/070212.php > Acessado em março/2007.

GIORDANO, S. R.; SPERS, E. E. Competitividade do Sistema Agroindustrial do Arroz. In: Farina, E.M.M.Q.; Zylbersztajn, D. (Coord.), vol. III. São Paulo. PENSA/FIA/FEA/USPIPEA. Julho, 1998. Versão Final. Disponível em: < http://www.pensa.com.br/pdf/relatorios/ ipea/Vol_III_Arroz.PDF>.

INSTITUTO BRASILEIRO DE GEOGRAFIA E ESTATÍSTICA. SIDRA. Disponível em: $<$ http://www.sidra.ibge.gov.br> Acesso em julho/2005.

KAYSER, V. H.; RUCATTI, E. G. Beneficiamento do Arroz no Rio Grande do Sul. SOSBAI. III Congresso Brasileiro de Arroz Irrigado. Santa Maria, 2004. Disponível em: < http:// www.sosbai.com.br> Acesso em julho/2005.

MINISTÉRIO DO DESENVOLVIMENTO INDÚSTRIA E COMÉRCIO - MDIC. Disponível em: $<$ http://www.desenvolvimento.gov.br/sitio/inicial/index.php > Acesso em fevereiro/2007.

MIRANDA, S. H. G. Perspectivas para o Mercado de Arroz. Palestra. Seminário Perspectivas para o Agribusiness 2006/07. BMEZF/MAPA: São Paulo, 04/05/06. Disponivel em: < http://www. cepea.esalq.usp.br/arroz/Perspectiva\%20do\%20mercado\%20de\%20arroz\%20BMF.pdf>.

MIRANDA, S. H. G.; SILVA, G. S.; FERREIRA, C. M. Indicadores da eficiência da comercialização do arroz de terras altas e irrigado no Brasil. Pôster. II Congresso Brasileiro da Cadeia Produtiva de Arroz e VIII Reunião Nacional de Pesquisa de Arroz, período de 26 a 28 de abril de 2006. EMBRAPA: Brasília, 26 de abril de 2006.

OLIVEIRA, C. F. (Coord.) Censo da Lavoura de Arroz Irrigado do Rio Grande do Sul - Safra 2004/05. Porto Alegre: IRGA - Política Setorial, 2006. 122p.

PEREIRA, F. L.; SILVA, G. S.; SPLENDORE, D.; MIRANDA, S. H. G. As perspectivas das exportações de arroz para o equilíbrio no mercado doméstico brasileiro. SIICUSP. $13^{\circ}$. Simpósio Internacional de Iniciação Cientifica da USP. 8 a 9 de novembro de 2005. ESALQ/ USP: Piracicaba. Resumo. CD-ROM.

RUCATTI, E. G.; KAYSER, V. H. Produção e Disponibilidade de Arroz por Região Brasileira. IRGA. Sem data. Disponível em: <http://www.irga.rs.gov.br/arquivos/prod_disp_arroz.pdf > Acesso em julho/2005. 12p.

YOKOYAMA, L. P.; FERREIRA, C. M. Cadeia produtiva do arroz na Região Centro-Oeste. Goiânia: Embrapa, 1999. 110p.

ZYLBERSZTAJN, D.; FARINA, E. M. M. Q.; SANTOS, R. C. O Sistema Agroindustrial do Café. Porto Alegre: Ortiz, 1993. 277p.

Recebido em 10/07/2008. Aceito em: 10/08/2008. 